\title{
PENINGKATAN PRODUKTIVITAS MASYARAKAT MELALUI TEKNOLOGI TEPAT GUNA BAGI PENINGKATAN EKONOMI MASYARAKAT BERDASARKAN KEARIFAN BUDAYA LOKAL DI DESA KADUBEREUM KECAMATAN PADARINCANG
}

\author{
Erni Krisnaningsih \\ Universitas Banten Jaya, Jl. Syech Nawawi Albantani Serang Banten \\ Email: ernikrisnaningsihpaidi@unbaja.ac.id
}

\begin{abstract}
Improving the standard of living is one of the most important factors in community survival. This must continue to be supported along with developments and competitiveness in the current era of globalization. Based on the results of mapping / assessment, it is known that Kadubereum Village has abundant natural potential, but it has not been supported by skilled human resources, especially in terms of traditional food processing, natural tourism management, and delivery of information through internet media. So that the living conditions of the community, especially in the economic aspects are not yet adequate, this is caused by several factors such as the still poor quality of human resources and inadequate village infrastructure. The main objective in this service activity is to provide Training and Counseling to the people of Kadubereum Village. What is done both in theory and practice in an effort to Improve Community Economy Through activities to increase community productivity through appropriate technology for improving the community's economy based on local cultural wisdom. With this kind of activity, it is expected to improve the economy and stimulate the creation of innovation and creativity to create superior local products and the development of natural attractions.
\end{abstract}

Keywords: Economy, Skills, Local Products, Nature Tourism.

\begin{abstract}
ABSTRAK
Meningkatkan taraf hidup menjadi salah satu faktor yang sangat penting dalam kelangsungan hidup bermasyarakat. Hal ini harus terus di dukung seiring perkembangan dan daya saing pada era globalisasi saat ini. Berdasarkan hasil pemetaan / assessment diketahui bahwa Desa Kadubereum memiliki potensi alam yang melimpah, namun belum didukung oleh sumber daya manusia yang terampil terutama dalam hal pengolahan makanan tradisional, pengelolaan wisata alam, dan penyampaian informasi melaui media internet. Sehingga kondisi kehidupan masyarakat, terutama pada aspek ekonomi belumlah memadai, hal ini disebabkan oleh beberapa faktor seperti kondisi kualitas SDM yang masih rendah dan infrastruktur desa yang juga belum memadai. Tujuan utama dalam kegiatan pengabdian ini adalah memberikan Pelatihan dan Penyuluhan kepada masyarakat Desa Kadubereum. Yang dilakukan baik secara teori maupun praktik dalam upaya Peningkatan Ekonomi Masyarakat Melalui kegiatan peningkatan produktivitas masyarakat melalui teknologi tepat guna bagi peningkatan ekonomi masyarakat berdasarkan kearifan budaya lokal. Dengan adanya kegiatan semacam ini, diharapkan dapat meningkatkan perekonomian dan menstimulasi terciptanya inovasi dan kreativitas untuk menciptakan produk lokal unggulan dan pengembangan obyek wisata alam.
\end{abstract}

Kata Kunci: Perekonomian, Keterampilan, Produk lokal, Wisata Alam. 


\section{PENDAHULUAN}

Kuliah Kerja mahasiswa (KKM) tematik Universitas Banten Jaya tahun 2019 mulai di laksanakan pada tanggal 1 Agustus 2019, di awali dengan pelepasan seluruh peserta KKM Tematik 2019 secara serentak oleh Panitia KKM Tematik 2019 dan oleh Asda kabupaten Serang di halaman pendopo Bupati Serang dan berakhir pada tanggal 31 Agustus 2019, Pada KKM tematik tahun 2019 ini, Lokasi pengabdian masyarakat di laksanakan di Desa Kadubereum yang terletak di Kecamatan Padarincang, Kabupaten Serang, Provinsi Banten. Desa Kadubereum memiliki luas 713 Ha berada yang berada pada koordinat $\mathrm{S}=6^{\circ} 22^{\prime} 01.19^{\prime}$ ' $\mathrm{E}=105^{\circ} 94^{\prime} 04.95^{\prime}$.

Pada masa yang telah lampau, Desa Kadubereum belum terbentuk, Desa Kadubereum Merupakan pemekaran dari Desa Cibojong dan mulai terbentuk pada Tahun 1983 di Pimpin oleh lurah SUPAHAR sebagai PJS. Pada saat itu masyarakat masih banyak yang belum mengerti sistem pemerintahan desa yang di rancang oleh pemerintah pusat sehingga masyarakat terkesan masih Ortodox dan belum mengetahui tentang pengetahuan dan pradaban modern. Pada tahun 1984 masyarakat Kadubereum pertamakali mengadakan pemilihan umum kepala desa yang kemudian masih di pimpin oleh Kades Supahar sampai dengan tahun 1993, keadaan masyarakat mulai terbuka akan kemajuan jaman tetapi dari segi pembangunan nspratuktur masih belum terlaksana.

\section{METODE}

Metode pelaksanaan pengabdian kepada masyarakat yang dilakukan melalui peningkatan produktivitas masyarakat melalui teknologi tepat guna bagi peningkatan ekonomi masyarakat berdasarkan kearifan budaya lokal terbagi atas 2 kegiatan, yaitu:

1. Assessment (KajianAwal/ Analisis Situasi).

Salah satu metode dalam Assessment adalah PRA. Waktu Pelaksanaan bulan Juni 2019. Participatory Rural Appraisal (PRA) adalah penilaian/ pengkajian/ observasi keadaan desa secara partisipatif. Maka dari itu, metode PRA adalah cara yang digunakan dalam melakukan pengkajian/penilaian /observasi untuk memahami keadaan atau kondisi desa/wilayah/lokalitas tertentu dengan melibatkan partisipasi masyarakat. PRA merupakan metode dan pendekatan pembelajaran mengenai kondisi dan kehidupan desa/wilayah/lokalitas dari, dengan dan oleh masyarakat sendiri dengan catatan : (1) Pengertian belajar, meliputi kegiatan menganalisis, merancang dan bertindak; (2) PRA lebih cocok disebut metode-metode atau pendekatan -pendekatan (bersifat jamak) daripada metode dan pendekatan (bersifat tunggal); dan (3) PRA memiliki beberapa teknik yang bisa kita pilih, sifatnya selalu terbuka untuk menerima cara-cara dan metode-metode baru yang 
dianggap cocok. Jadi pengertian PRA adalah sekumpulan pendekatan dan metode yang mendorong masyarakat di suatu desa/wilayah/lokalitas untuk turut serta meningkatkan dan menganalisis pengetahuan mereka mengenai hidup dan kondisi mereka sendiri agar mereka dapat membuat rencana dan tindakan. Pelaksanaan kegiatan pengabdian ini dilaksanakan dalam upaya peningkatan ekonomi masyarakat melalui peningkatan produktivitas melalui teknologi tepat guna berdasarkan kearifan budaya lokal. Yakni dengan menumbuhkan inovasi-inovasi dalam mengembangkan makanan tradisional asli desa, memperbaiki destinasi wisata curug cikotak, dan pembuatan WEB Desa sebagai sarana informasi desa dan promosi destinasi wisata dan produk masyarakat. Dalam pelaksanaannya, kegiatan pengabdian ini dilaksanakan dengan memberikan pelatihan secara langsung dipraktikkan kepada masyarakat, pembenahan destinasi wisata, dan pembuatan web desa.

2. Pelatihan Kewirusahaan, Pembenahan Destinasi Wisata, dan Pembuatan Web Desa

Metode pelaksanaan kegiatan kewirausahaan yaitu menggunakan metode pelatihan, dengan dilengkapi alat bantu seperti laptop, proyektor, alat praga berupa produk yang sudah di kemas, dan lain-lain. Pelatihan dan penyuluhan ini dilaksanakan oleh tim pengabdian sebagai narasumber, dibantu oleh mahasiswa Unbaja. Pada kegiatan pelatihan ini narasumber memberikan materi dengan menjelaskan dan memberikan contoh-contoh sederhana mengenai kewirausahaan terutama mengenai strategi-strategi dalam pemasaran produk. Selain itu juga kami sebagai narasumber memberikan pengetahuan tentang bagaimana membuat inovasi produk. Agar makanan tradisional tidak itu melulu dan terkesan monoton, yang selama ini diolah menjadi makanan yang belum banyak variasinya. Dengan kegiatan pengabdian ini, tim memberikan pelatihan bagaimana mengolah daging ayam menjadi berbagai macam variasi bakso. Sehingga bahan dasar makanan daging ayam ini dapat bernilai ekonomi tinggi. Dan dapat dipasarkan serta dikenal sebagai makanan khas masyarakat setempat, selain makanan hasil olahan lainnya yang sudah ada sebelumnya. Tim juga dalam pelatihan ini, memberikan sesi tanya jawab kepada para peserta mengenai permasalahan-permasalahan dan peluang untuk berwirausaha.

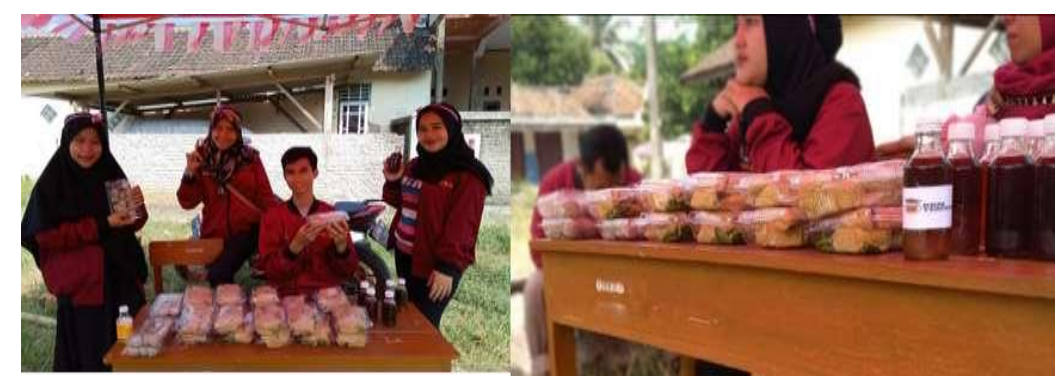

Gambar 1. Produk Makanan Khas Desa Kadubereum 
Alat yang digunakan dalam kegiatan ini adalah Laptop, proyektor, layar proyektor. Sedangkan bahan yang digunakan adalah berupa makanan tradisional yang sudah di oleh oleh tim pengabdian berupa olahan daging ayam menjadi berbagaimacam varian bakso dengan tampilan kemasan yang lebih menarik. Metode kegiatan pembenahan destinasi wisata Curug Cikotak dengan membuat spot foto untuk membuat lokasi wisata menjadi lebih menarik dan dapat menarik masyarakat untuk berkunjung di Curug Cikotak. Pada kegiatan ini tim pengabdian dibantu oleh mahasiswa Unbaja dan pemuda desa. Diharapkan setelah adanya spot foto yang baru akan membuat Curug Cikotak semakin banyak pengunjung dan dapat lebih di kenal masyarakt di luar desa Kadubereum.

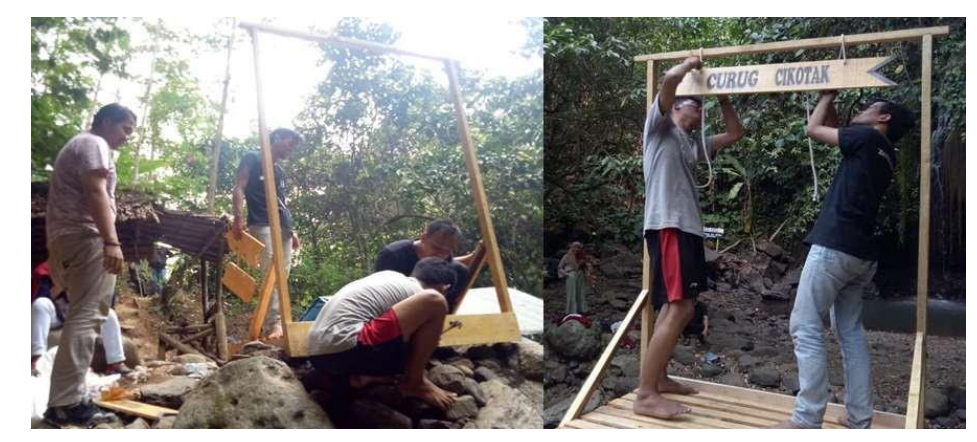

\section{Gambar 2 Proses Pembuatan Spot Foto Curug Cikotak}

Alat yang digunakan dalam kegiatan pembenahan destinasi wisata Curug Cikotak berupa gergaji kayu, palu, sendok bata, kuas cat dan mesin penghalus kayu. Sedangkan bahan yang digunakan adalah kayu jati belanda, paku, semen, pasir, batu kali, tali tambang, cat vernis, amplas, dan lain-lain. Metode pelaksanan pembuatan web desa adalah dengan melakukan analisa dan perancangan pemrograman dengan teknik prototype. Dimana tim pengabdian merancang program web desa berdasarkan hasil wawancara dengan perangkat Desa dan masyarakat kemudian di simpulkan kebutuhan informasi yang akan di tampilkan pada web Desa. Setelah program web desa selesai di buat kemudian di presentasikan kepada aparat desa hasil program tersebut untuk mendapatkan sinkronisasi kebutuhan web apakah sudah sesuai dengan yang di butuhkan oleh Desa Kadubereum. Apabila masih ada kekurangn pada program web maka akan di lakukan penambahan konten dan pengambangan program web sampai dengan semua konten telah sesuai dengan kebutuhan di Desa Kadubereum. Hal ini sesuai dengan konsep pengembangan sistem menggunakan metode prototype. Alat yang digunakan dalam kegiatan pembuatan web desa adalah laptop, 
sotware pemrograman web, proyektor, dan printer. Sedangkan bahan yang di gunakan kertas untuk mencetak hasil program yagn sudah dibuat guna di konsultasikan kepada aparat desa.

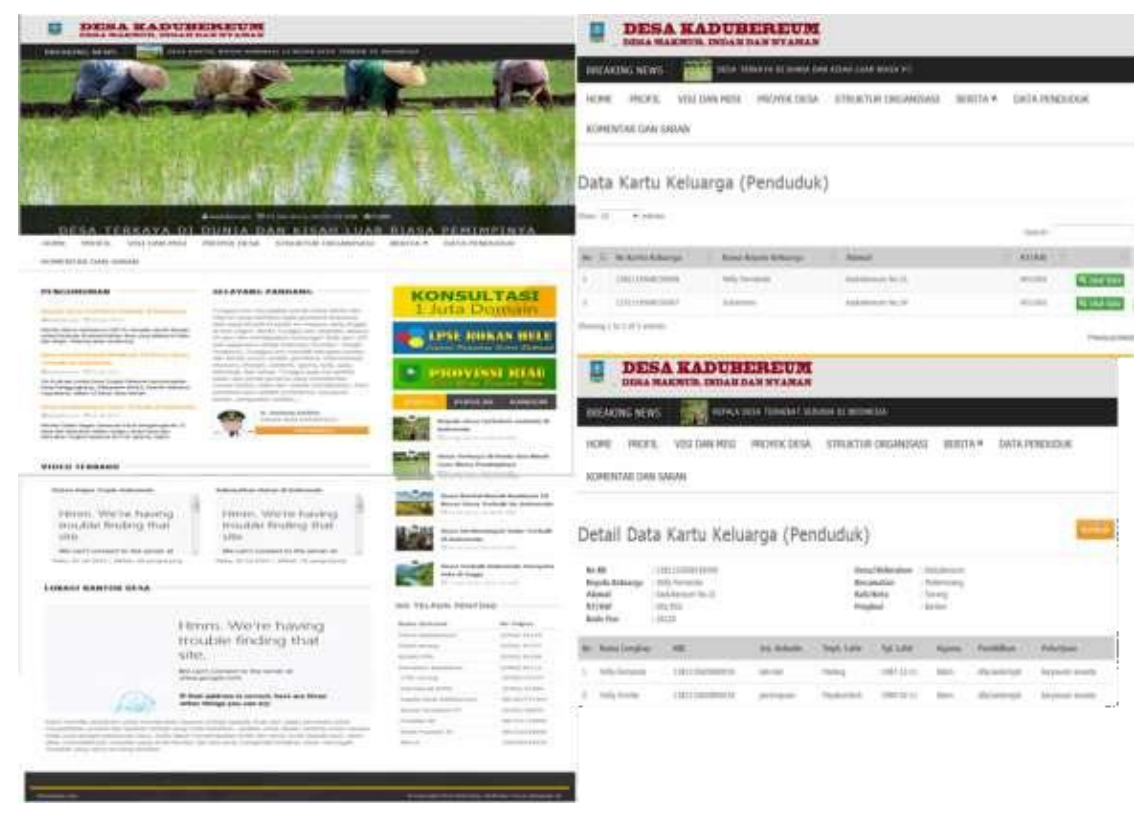

\section{Gambar 3. Tampilan Web Desa Kadubereum Kecamatan Padarincang}

\section{HASIL DAN PEMBAHASAN}

Kegiatan pengabdian masyarakat yang dilakukan di Desa Kadubereum Kecamatan Pabuaran Kabupaten Serang Provinsi Banten telah dilaksanakan dengan lancar dan dengan hasil yang cukup baik. Berdasarkan uraian pada bagian sebelumnya metode pelaksanaan kegiatan yang dilakukan dengan dua cara maka kami memperoleh hasil sebagai berikut:

\section{Tahap Assesment}

Berdasarkan hasil assesment dari kegiatan pemetaan yang dilaksanakan di Desa Kadubereum, terutama mengenai kondisi berbagai aspek kehidupan masyarakat. Kondisi Keagamaan, umumnya penduduk Desa Kadubereum adalah pemeluk Agama Islam, saat ini sudah ada pengajian yang dilaksanakan secara rutin yaitu malam Jumat. Kondisi Pendidikan, sarana sekolah/gedung sudah ada mulai dari pendidikan usia dini (PAUD) hingga SMP. Masalah yang muncul adalah masih tingginya penduduk dengan latar belakang pendidikan dasar. Pola pikir masyarakat setempat yang masih beranggapan bahwa pendidikan bukan menjadi kebutuhan dan keharusan menjadikan masyarakatnya masih berpendidikan rendah. Selain itu bangunan atau gedung sekolah masih ada yang perlu perbaikan. 
Kondisi Kesehatan, Desa Kadubereum sudah ada layanan kesehatan berupa Posyandu namun untuk ke puskesmas jarak yang di tempuh cukup jauh, terdapat program Jamkesmas untuk RTM dan RTSM. Masalah yang muncul adalah warga belum memahami tentang manfaat dari Posyandu, warga juga belum memiliki perilaku hidup yang sehat, seperti belum terbiasanya untuk BAB di MCK. Dan masih banyak Rumah Tangga yang belum memiliki tempat MCK. Di Desa Kadubereum juga berpotensi untuk dikembangkan sektor peternakan dan perikanan air tawar, namun dengan kondisi potensi tersebut ternyata masih ada beberapa masalah terkait dengan aspek pertanian, diantaranya hasil pertanian terutama padi dirasakan masih kurang, hal ini disebabkan masih minimnya pengetahuan warga mengenai pengelolaan pertanian, harga pupuk yang mahal dan hama tanaman. Kondisi Ekonomi, warga masyarakat di Desa Kadubereum belum memiliki keterampilan dalam membuat beragam olahan makanan dengan bahan baku yang sebetulnya sangat melimpah dari alam. Sedangkan masalah yang muncul adalah terkait inovasi dan pemasaran yang kurang maksimal untuk pengolahan bahan makanan terutama berbahan dasar daging ayam yang menjadi komoditas utama di Desa Kadubereum.

Hal ini lah yang menyebabkan perekonomian masyarakat belum seutuhnya terangkat atau sejahtera. Kondisi Sarana/Prasarana Desa Kadubereum memang sudah ada akses untuk menuju Kantor Kelurahan maupun wilayah pemukiman warga, hanya saja kondisi jalan yang kebanyakan naik turun bukit dan sebagain tidak memiliki parit (saluran air) sehingga ketika musim hujan datang akan terjadi genangan air dan licin. Sedangkan untuk sarana irigasi umumnya adalah irigasi non teknis yang masih berupa selokan tanah, sehingga mudah terjadi penyempitan dan longsor. Kondisi Sosial, posisi tokoh masyarakat atau sesepuh masih memegang peranan penting dalam kehidupan bermasyarakat. Selain itu, nilai-nilai kebersamaan yang dianut oleh warga antara lain saling membantu sesama, saling menolong, peduli, dan saling percaya, demikian juga dengan budaya gotong royong atau kerjasama. Seiring dengan perkembangan jaman, kondisi ini lambat laun terus berubah terutama pada kalangan remaja dan pemuda. Pengaruh budaya luar dinilai dapat menggeser nilai-nilai budaya asli masyarakat seperti kenakalan remaja, pergaulan bebas, konflik dan sebagainya.

Kondisi ini diperparah lagi oleh makin tingginya angka pengangguran terutama pada kalangan remaja dan pemuda yang disebabkan oleh lapangan kerja yang terbatas dan kurang sesuainya keterampilan dengan lapangan pekerjaan. Kondisi Kelembagaan, hasil pemetaan menunjukan bahwa kondisi kelembagaan pemerintah desa baik dari segi SDM maupun sarana bangunan belum memadai, kondisi SDM perlu ada peningkatan kualitas 
demikian juga dengan kondisi bangunan memerlukan perbaikan- perbaikan sehingga dapat meningkatkan kualitas layanan kepada masyarakat, Kondisi 80esehat 80esehatan memang sudah ada Posyandu. Namun warga menilai bahwa keberadaan posyandu ini belum maksimal, hal ini disebabkan sarana dan prasarana yang belum memadai.

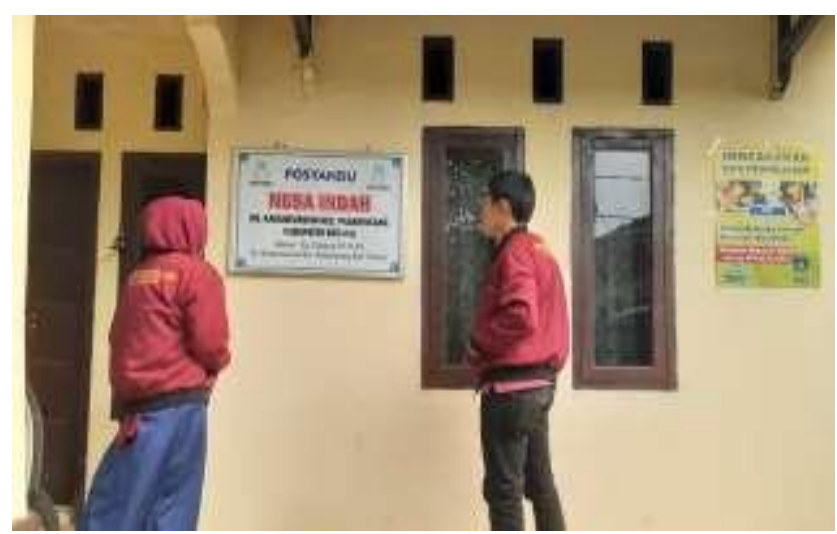

Gambar 4 Lokasi Posyandu

\section{Tahap Pelatihan}

Hasil dari pelatihan ini masyarakat menjadi lebih mengetahui dan memahami tentang masalah-masalah yang berkaitan erat tentang bagaimana membuat bahan dasar komoditas lokal dalam hal ini berbahan dasar daging ayam menjadi produk yang berinilai ekonomi tinggi. Dalam pelaksanaan pelatihan dan penyuluhan ini juga masyarakat warga Desa Kadubereum sebagai lokasi kegiatan pengabdian, sangat antusias dan merespon dengan baik diselengarakannya kegiatan pelatihan ini. Hal tersebut dapat dibuktikan dengan banyaknya peserta yang hadir dan pada saat kegiatan berlangsung, masyarakat senang dan banyak melontarkan pertanyaan yang di tujukan kepada Narasumber seputar materi yang telah diberikan. Masyarakat juga berharap agar diadakan kembali acara serupa di Desa Kadubereum ke depannya.

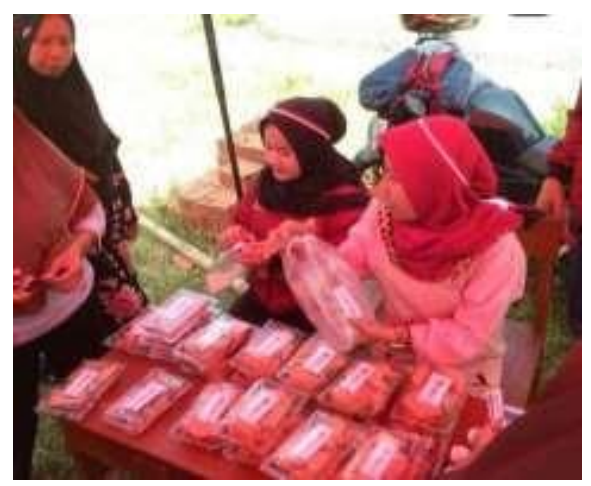

Gambar 5 Salah Satu Bentuk Kemasan Produk Makanan Khas Desa Kadubereum 


\section{Rencana Keberlanjutan Program}

Berdasarkan dari hasil kegiatan pengabdian yang telah dilakukan, terutama kegiatan pelatihan mengenai keterampilan pengolahan bahan dasar daging ayam menjadi produk inovasi berupa bakso, nampaknya perlu diadakan kegiatan yang bertujuan untuk meningkatkan kreatifitas berupa membuat kemasan hasil/produk yang lebih menarik dari kemasan yang sudah dibuat sebelumnya, dengan melibatkan lagi team pengabdian dan mahasiswa yang berlatar belakang ilmu komputer untuk mendesain kemasan produk. Selain itu memberikan wawasan tentang bagaimana agar produk ini diakui oleh dinas-dinas terkait. Agar dapat diberikan izin dan sebagainya. Sehingga nantinya produk yang dipasarkan sudah memiliki legalitas minimal dari pemerintah kabupaten. Kegiatan pelatihan tersebut juga dapat dibarengi dengan kegiatan memaksimalkan sumber daya kelompok usaha yang telah ada atau pembentukan kelompok baru dengan memberdayakan masyarakat di Desa Kadubereum, terutama kaum ibu-ibu. Untuk selanjutnya Tim melakukan pendampingan dan pemantauan terkait perkembangan kelompok usaha yang telah dibentuk sebelumnya. Untuk destinasi wisata Curug Cikotak perlu ada pengambangan dan perapian destinasi wisata tersebut. Khususnya akses jalan menuju obyek wisata Curug Cikotak yang masih berupa jalan tanah. Dimana kalau musim hujan makan jalan menjadi licin dan membahayakan bagi pengunjung karena akses jalan sebagian besar menyusuri bukit yang curam.

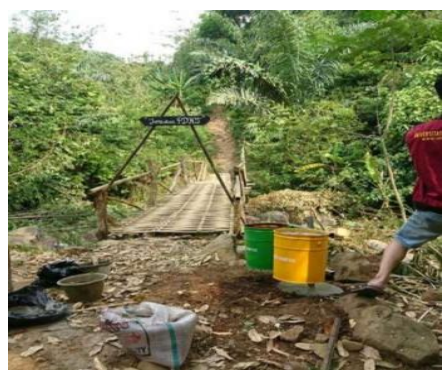

\section{Gambar 6 Salah Jalan dan Jembatan Menuju Curug Cikotak}

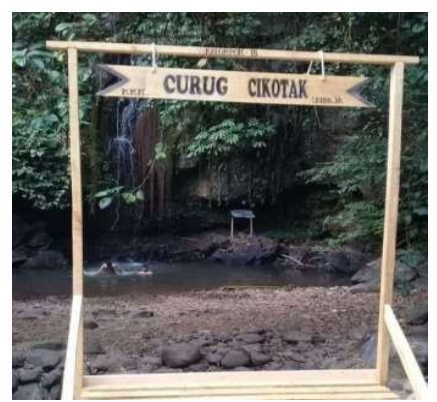

Gambar 7. Spot Foto Curug Cikotak 


\section{KESIMPULAN}

Berdasarkan berbagai kegiatan yang telah dilaksanakan, secara keseluruhan dapat disimpulkan bahwa sebagian besar program pengabdian berjalan dengan baik. Mulai dari tahap assesment hingga pelaksanaan tahap pelatihan, pembenahan destinasi wisata, dan pembuatan web desa. Hasilnya, ibu-ibu peserta pelatihan dapat mengikuti kegiatan dengan sangat antusias dan dapat membuat bakso sebagai produk hasil inovasi kegiatan ini dengan baik, sehingga diharapkan dapat menularkan kepada ibu-ibu lain yang berhalangan hadir pada pelaksanaan kegiatan pengabdian. Untuk destinasi wisata Curug Cikotak bertambah fasilitas untuk spot foto sehingga akan mengundang banyak wisatawan untuk berkunjung. Pembuatan web desa berdampak pada informasi sumber daya masyarakan maupun sumber daya alam Desa Kadubereum semakin di kenal oleh masyarakat luas.

\section{UCAPAN TERIMAKASIH}

Ucapan terimakasih disampaikan kepada :

1. Kepala Desa Kadubereum yang telah bekerjasama dan memberikan kesempatan kepada team pengabdian untuk dapat melaksanakan pengabdian di desa Kadubereum.

2. LPPM, Dosen Tim Pengabdian, dan Mahasiswa Unbaja yang telah bekerjasama dalam pelaksanaan kegiatan ini sebagai narasumber maupun fasilisator dan pelaksana kegiatan.

\section{DAFTAR PUSTAKA}

Buku Panduan, Kuliah Kerja Mahasiswa (KKM) TEMATIK Univeritas Banten Jaya, 2019.

Jurnal Studi Uji Karakteristik Fisis Briket Bioarang Sebagai Sumber Energi Alternatif. Online Jurnal of Natural Science, Vol.3(1): 89-98 ISSN: 2338-0950 March 2014.

Jurnal, Kajian Kualitas Briket Biomassa dari Sekam Padi dan Tempurung Kelapa , Jurnal Kimia VALENSI: Jurnal Penelitian dan Pengembangan Ilmu Kimia, 2 (2), November 2016, 136-142.

Jurnal, Pembuatan Briket Bioarang Dari Cangkang Dan Tandan Kosong Kelapa Sawit, Jurnal Teknologi Hasil Pertanian, Vol. VI, No.2, Agustus 2013. 